\title{
Recovery of Silver from Waste Silver Chloride for the MEO System
}

RECEIVED

JUN 271996

OSTI

Peter C. Hsu, Zoher Chiba, Bruce J. Schumacher, Laura C. Murguia, and Martyn G. Adamson

February 1996

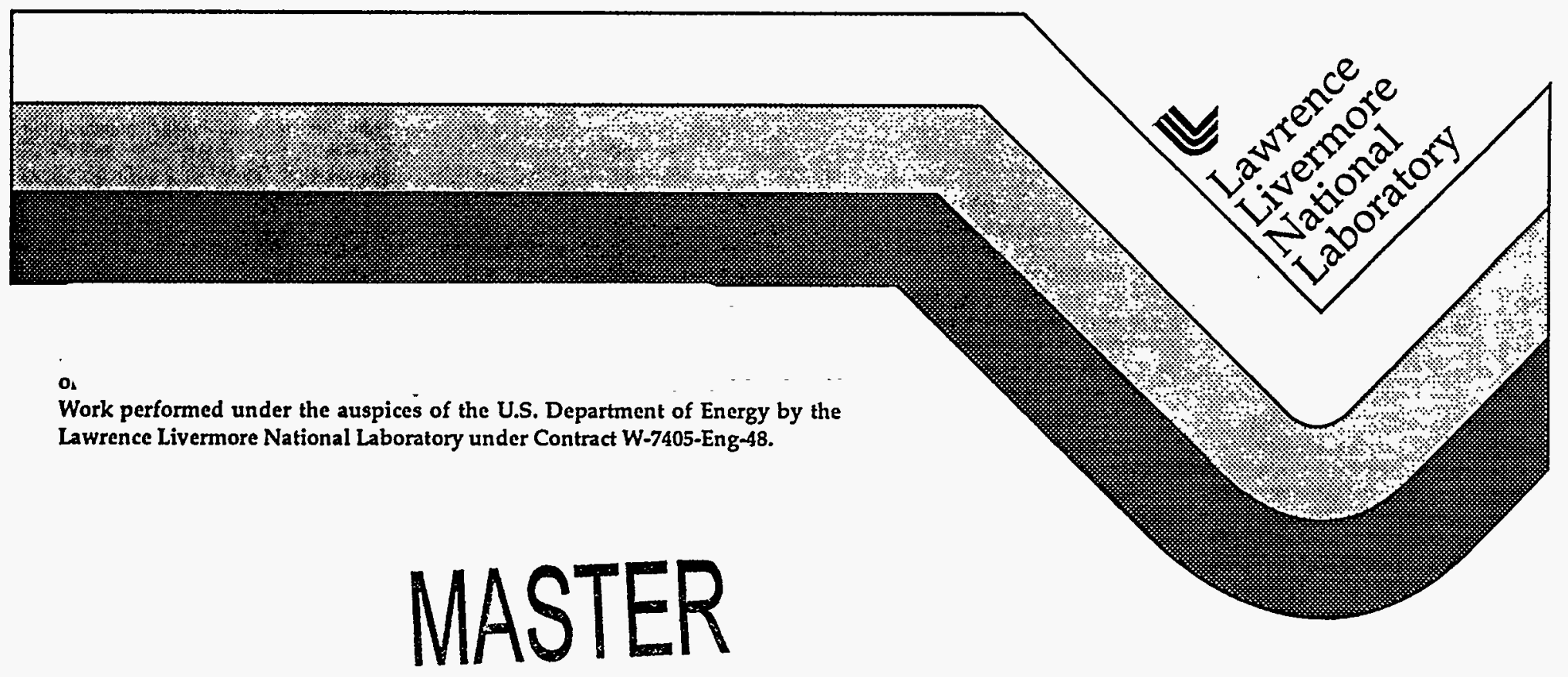

MSTRIBUTION OF THIS DOCUMENT IS UNLIMITED 


\section{DISCLAIMER}

This document was prepared as an account of work sponsored by an agency of the United States Government. Neither the United States Government nor the University of California nor any of their employees, makes any warranty, express or implied, or assumes any legal liability or responsibility for the accuracy, completeness, or usefulness of any information, apparatus, product, or process disclosed, or represents that its use would not infringe privately owned rights. Reference herein to any specific commercial product, process, or service by trade name, trademark, manufacturer, or otherwise, does not necessarily constitute or imply its endorsement, recommendation, or favoring by the United States Government or the University of California. The views and opinions of authors expressed herein do not necessarily state or reflect those of the United States Government or the University of California, and shall not be used for advertising or product endorsement purposes.

This report has been reproduced directly from the best available copy.

Available to DOE and DOE contractors from the Office of Scientific and Technical Information

P.O. Box 62, Oak Ridge, TN 37831

Prices available from (615) 576-8401, FTS 626-8401

Available to the public from the National Technical Information Service

U.S. Department of Commerce 5285 Port Royal Rd. Springfield, VA 22161 


\title{
Recovery of Silver from Waste Silver Chloride for the MEO System
}

\author{
Peter C. Hsu, Zoher Chiba, Bruce J. Schumacher, \\ Laura C. Murguia, and Martyn G. Adamson \\ Lawrence Livermore National Laboratory \\ Livermore, CA 94550
}

\section{Introduction}

Mediated Electrochemical Oxidation (MEO) is a non-thermal, aqueous process that treats mixed wastes by oxidizing the organic components of the waste into carbon dioxide and water via chemically active metallic ions (mediators). The MEO process is ideally suited for treating liquid and aqueous mixed wastes. For chlorinated organic wastes, the chlorine will bind with mediator (silver) in the solution to form an insoluble silver chloride. The silver chloride is then separated from the MEO primary system by centrifugation. Replenishment of silver ions into the MEO system is also required to ensure destruction efficiency of MEO process. Since silver is a land-ban metal and it is fairly expensive, an efficient recovery process which converts silver chloride into silver nitrate is required. The integration of the silver recovery into the $\mathrm{MEO}$ process would avoid the costly silver make-up to the MEO system and also minimized the discharge of silver to the environment.

\section{Process Selection}

It is desirable that the silver recovery method used in MEO be low temperature and aqueous to prevent volatilization of radionuclides. A desirable process should also have high conversion efficiency, not add appreciably to the waste stream, and be economical. In general, there are two steps in all of the aqueous conversion processes we considered for implementation in the MEO System:

(a) Reduction of $\mathrm{AgCl}$

$$
\mathrm{AgCl} \longrightarrow-\cdots \mathrm{Ag}
$$

(b) Dissolution of Ag

$$
\mathrm{Ag}-\cdots \mathrm{AgNO}_{3}
$$


Step (b) is fairly straightforward, the resulting solution $\mathrm{AgNO}_{3} / \mathrm{HNO}_{3}$ will be sent back to the MEO primary system for reuse. Step (a), however, can be accomplished by a number of methods which were considered and are reviewed below. In general, all of the aqueous recovery methods, except for the method selected for MEO, have undesirable features such as adding organics or toxic metals to the waste stream or involve hazardous reagents.

\section{Review of Aqueous Silver Chloride Reduction Methods}

There are many methods available in literature. Here is a brief review of these methods.

\section{(1) Formaldehyde Method}

Formaldehyde and sodium hydroxide are required for this method. The reaction is shown as follows:

$$
\begin{aligned}
& 2 \mathrm{AgCl}+3 \mathrm{NaOH}+\mathrm{HCHO} \rightarrow 2 \mathrm{Ag}+\mathrm{HCOONa}+2 \mathrm{NaCl}+2 \mathrm{H}_{2} \mathrm{O} \\
& 2 X \quad 2 X
\end{aligned}
$$

$100 \%$ excess of sodium hydroxide and formaldehyde is used for the reduction, consequently, secondary wastes, such as $\mathrm{HCHO}, \mathrm{HCOONa}$, and $\mathrm{NaCl}$ are problematic.

\section{(2) Sodium Borohydride Method}

Sodium borohydride is used to reduce silver chloride to silver. A vigorous reaction takes place with hydrogen evolution. The reaction is shown below:

$$
2 \mathrm{AgCl}+\underset{1.13 \mathrm{X}}{2 \mathrm{NaBH}_{4}}+\underset{6 \mathrm{H}_{2} \mathrm{O}-->>\mathrm{Ag}}{2}+2 \mathrm{H}_{3} \mathrm{BO}_{3}+2 \mathrm{NaOH}+7 \mathrm{H}_{2}
$$

The problems with this method are residual sodium borohydride (due to the $13 \%$ excess), product boric acid and the rigorous release of hydrogen. In addition, if not carefully stored and handled, Sodium borohydride can be a fire hazard.

\section{(3) Zinc Method}

Zinc powder is a good reducing agent in the presence of liquid media sodium hydroxide, hydrochloric acid, or ammonia. The reactions are shown in the following, respectively:

$$
\begin{aligned}
& 2 \mathrm{AgCl}+4 \mathrm{NaOH}+\mathrm{Zn} \rightarrow-\mathrm{N}^{2} \mathrm{Ag}+\mathrm{Na}_{2} \mathrm{Zn}(\mathrm{OH})_{4}+2 \mathrm{NaCl} \\
& 1.3 X \\
& \mathrm{AgCl}+\mathrm{HCl}+\mathrm{Zn}--->\mathrm{Ag}+\mathrm{ZnCl}_{2}+\mathrm{H}_{2} \\
& 1.3 \mathrm{X}
\end{aligned}
$$


$\mathrm{AgCl}+2 \mathrm{NH}_{4} \mathrm{OH}+\mathrm{Zn} \longrightarrow \mathrm{Ag}+\mathrm{NH}_{4} \mathrm{Cl}+\left(\mathrm{NH}_{4}\right)_{2} \mathrm{Zn}(\mathrm{OH})_{4}$

$1.3 X$

The main problem with the zinc method is the presence of residual zinc and zinc compounds which are LDR.

\section{(4) Copper Method}

Silver chloride is dissolved in ammonia and can be reduced to silver by copper powder as shown below.

$\mathrm{AgCl}+2 \mathrm{NH}_{4} \mathrm{OH}+\mathrm{Cu} \rightarrow-->\mathrm{Ag}+\mathrm{NH}_{4} \mathrm{Cl}+\mathrm{NH}_{4} \mathrm{Cu}(\mathrm{OH})_{2}$

$1.04 \mathrm{X}$

Copper and copper compound are the problem as they are LDR.

(5) Benzaldehyde Method

Benzaldehyde can reduce silver chloride to silver in the presence of sodium hydroxide.

$2 \mathrm{AgCl}+\mathrm{C}_{6} \mathrm{H}_{5} \mathrm{CHOHSO}{ }_{3} \mathrm{Na}+4 \mathrm{NaOH}-\mathrm{CH}_{2} \mathrm{Ag}+\mathrm{C}_{6} \mathrm{H}_{5} \mathrm{COONa}+\mathrm{Na}_{2} \mathrm{SO}_{3}$ $+2 \mathrm{NaCl}+3 \mathrm{H}_{2} \mathrm{O}$

The problems with this method are organic wastes and sodium sulfite $\mathrm{Na}_{2} \mathrm{SO}_{3}$.

(6) Dextrose Method

Dextrose reduces silver chloride very effectively in the sodium hydroxide solution. However, residual organic wastes are undesirable.

$2 \mathrm{AgCl}+3 \mathrm{NaOH}+\mathrm{C}_{6} \mathrm{H}_{12} \mathrm{O}_{6} \longrightarrow 2 \mathrm{Ag}+2 \mathrm{NaCl}+\mathrm{C}_{6} \mathrm{H}_{11} \mathrm{O}_{7} \mathrm{Na}+2 \mathrm{H}_{2} \mathrm{O}$ 1.3X 1.15X

(7) Hydrogen Peroxide Method ( Selected Method)

Hydrogen peroxide is a reducing agent in alkaline solutions. It reduces silver chloride into metallic silver. The reaction is shown as follows:

$2 \mathrm{AgCl}+2 \mathrm{NaOH}+\mathrm{H}_{2} \mathrm{O}_{2}--\rightarrow 2 \mathrm{Ag}+2 \mathrm{NaCl}+2 \mathrm{H}_{2} \mathrm{O}+\mathrm{O}_{2}$

The advantages of this method are: 1 . chemicals are inexpensive, 2 . no exotic waste will be generated except sodium chloride, waste generation should be very small if low stoichiometry of $\mathrm{NaOH}$ is used. Despite its advantages, there is no quantitative information available in the literature. Therefore a lab-scale experiment was initiated to study this process. 


\section{Experiments}

\section{Chemical Reactions}

Silver chloride is reduced to metallic silver in alkaline solution by hydrogen peroxide. Silver is then separated from the solution, dissolved in nitric acid, and converted into silver nitrate.

\section{Reaction 1}

$$
2 \mathrm{AgCl}+2 \mathrm{NaOH}+\mathrm{H} 2 \mathrm{O} 2 \longrightarrow 2 \mathrm{Ag}+2 \mathrm{NaCl}+2 \mathrm{H} 2 \mathrm{O}+\mathrm{O} 2
$$

\section{Reaction 2}

$$
4 \mathrm{Ag}+6 \mathrm{HNO}_{3}----->4 \mathrm{AgNO}_{3}+\mathrm{NO}+\mathrm{NO}_{2}+3 \mathrm{H}_{2} \mathrm{O}
$$

\section{Procedures}

The procedures of the lab-scale experiments are shown in the Figure 1, Process Flow Diagram. Silver chloride was added into a solution of sodium hydroxide with mixing at $450 \mathrm{rpm}$. A heating plate was used to heat the solution to desirable temperatures. The solids turned to dark brown color, an indication of the formation of silver oxide. Hydrogen peroxide was then slowly added to the solution. Rigorous reaction occurred with foaming due to the release of oxygen. After the experimentally varied reaction time was reached, mixing was stopped. The solution was then sent to a filtering funnel or a centrifuge for solid/liquid separation. The liquid was analyzed for silver ions and chlorides. The solids which were metallic silver and unconverted silver chloride were then dissolved into nitric acid at 70 degrees $C$ under magnetic stirring for about 20 minutes. Unconverted silver chloride is insoluble in nitric acid and was filtered out and dried in an oven at 80 degrees. C over night. The conversion efficiency (yield) was calculated based on the amounts of starting and residual silver chloride. 
2. Process Flow Diagram (Fig. 1)

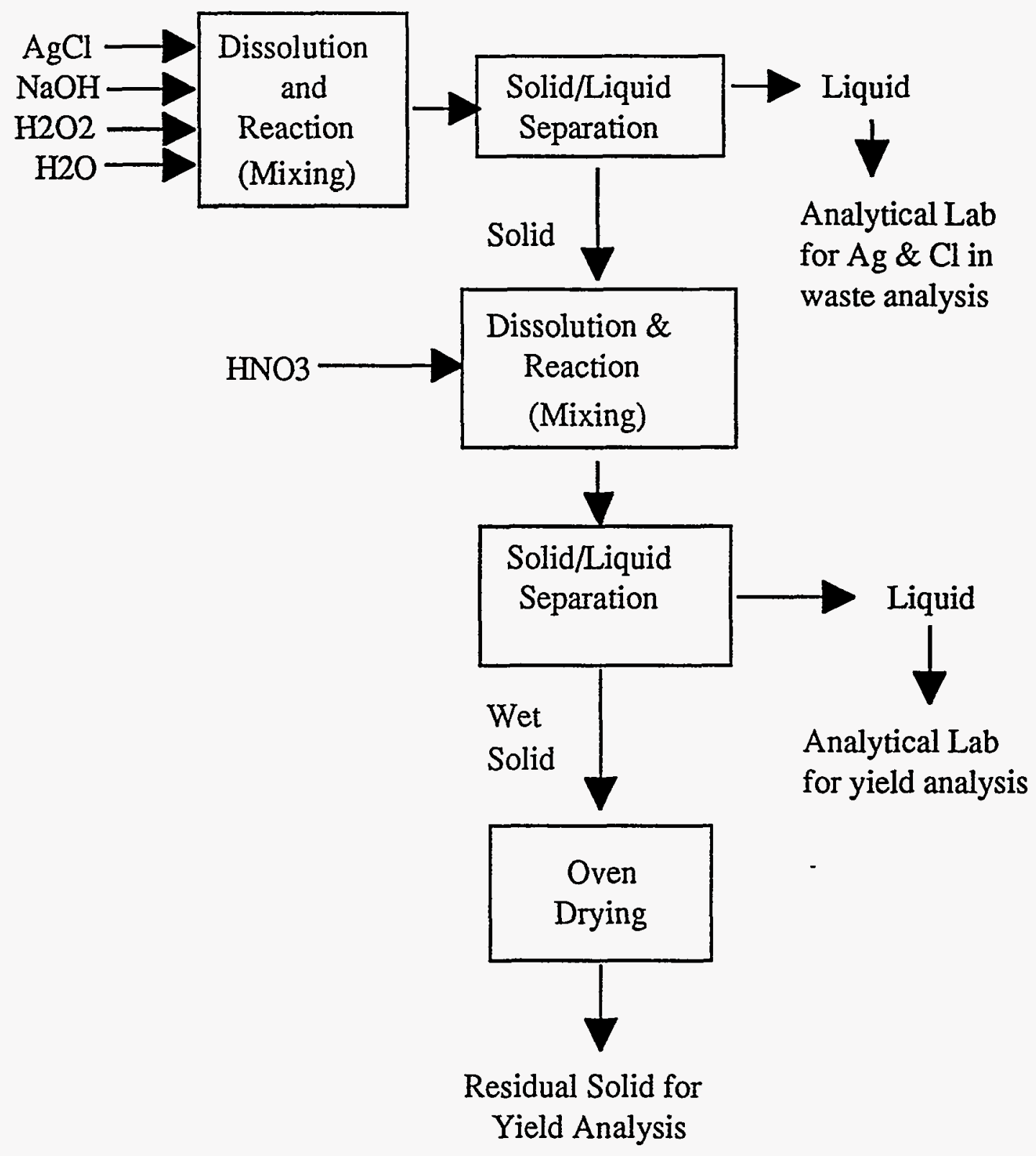

Conversion Efficiency (Yield) =

(1 - Residual AgCl Solid Out/AgCl into the Process) 


\section{Results}

\section{Conversion Efficiencies Vs. Stoichiometries of $\mathrm{NaOH} \& \mathrm{H}_{2} \mathrm{O}_{2}$}

Based on reaction (1), there are two ways to improve conversion efficiency theoretically, large amounts of $\mathrm{NaOH}$ or large amounts of $\mathrm{H}_{2} \mathrm{O}_{2}$. Both would shift the reaction equilibrium to the right hand side, consequently higher yield could be achieved.

Fig. 2 shows the conversion efficiencies at different $\mathrm{NaOH}$ stoichiometries. This curve indicates conversion efficiency is good at high stoichiometries such as 20 , but it will generate large amounts of secondary waste salt which is a product of the neutralization of the resulting alkaline solution. With external heating at 80 degrees $C$, high efficiency can be achieved at stoichiometry of 10 which is still high waste salt. The desirable $\mathrm{NaOH}$ stoichiometry is less than 2 to minimize the generation of additional waste. Stoichiometry of 1.25 with external heating was used. The conversion is about $80 \%$ which was not too bad, but it did not meet the goal, $90 \%$. Therefore we decided to keep $\mathrm{NaOH}$ stoichiometry at 1.25 and change the stoichiometry of $\mathrm{H}_{2} \mathrm{O}_{2}$.

Fig. 3 shows the effect of $\mathrm{H}_{2} \mathrm{O}_{2}$ stoichiometry on the conversion efficiency. It indicates that at $1.25 \mathrm{X} \mathrm{NaOH}$ stoichiometry with external heating at 80 degrees $\mathrm{C}, 98 \%$ conversion is achievable at $10.32 \mathrm{X} \mathrm{H}_{2} \mathrm{O}_{2}$ stoichiometry. The excess $\mathrm{H}_{2} \mathrm{O}_{2}$ is unstable and breaks down into water and oxygen, which are not undesirable additions to the waste stream.

Hence this is the optimal condition:

$\mathrm{NaOH}$ stoichiometry: $1.25 \mathrm{X}$

$\mathrm{H}_{2} \mathrm{O}_{2}$ stoichiometry: $10.32 \mathrm{X}$

\section{Conversion Efficiencies vs. Reaction Time}

Since hydrogen peroxide decomposes quickly in alkaline solutions at high temperatures, it will have a negative effect on the conversion due to the back reaction.

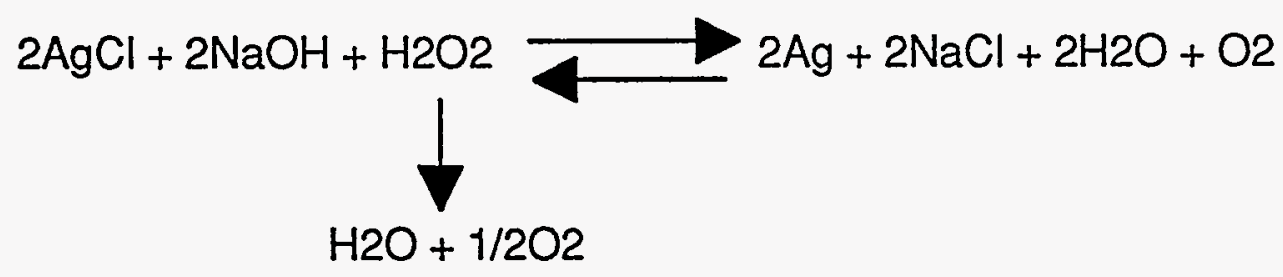

Fig. 4 shows the effect of reaction time on the conversion. The conversion efficiency decreases as the reaction time increases. Therefore, a careful control of reaction time is required. 


\section{Solution Reuse Study}

To minimize the discharge of waste water, reusing solution of reaction 1 may be desirable. This would have the affect of increasing the salt concentration in the waste water, but minimizing the volume of waste water. The purpose of the solution reuse study is to determine: (1) whether the solution is reusable?, and (2) concentrations of silver ions in the waste water, which are LDR and thus would be undesirable to add to the waste stream.

Fig. 5 shows that the solution can be reused several times under the optimal condition without any loss of conversion efficiency.

Fig. 6 indicates that the silver concentrations in the solution increase with increasing salt concentration as expected, but is still very low.

\section{Conversion Efficiencies without External Heating}

Table 1 shows the conversion efficiencies at optimal condition with and without external heating. The conversions are nearly identical. It indicates that the external heating is not required, and as a result, it will save utility cost for the pilot plant operation.

\section{Table 1}

Conditions Heating Conversions

$1.25 \times \mathrm{NaOH}$ $10.32 \mathrm{XH}_{2} \mathrm{O}_{2}$ 80 deg C, 15 min. $\quad 98.8 \%$

Same No heating $98.1 \%$

\section{Equipment Sizing for Pilot Plant Silver Recovery System}

(1) AgCl Dissolver Kettle

At the optimal condition, the amounts \& volumes of reagents used for the study are listed in Table 2

Table 2

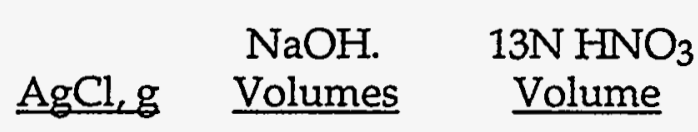

$\begin{array}{lrcl}\text { Lab Scale } & 28.6 & 0.185 \mathrm{~L} & 30 \mathrm{CC} \\ \text { Pilot Plant } & 12,500 & 81 \mathrm{~L} & 13 \mathrm{~L}\end{array}$

(2) $\mathrm{H} 2 \mathrm{O} 2$ Feed Pump 
To avoid excess foaming, the $\mathrm{H}_{2} \mathrm{O}_{2}$ feed rate must be controlled carefully. Table 3 shows that a $2.6 \mathrm{~L} / \mathrm{min}$. metering pump is required for the pilot plant.

Table 3

\section{$\underline{\mathrm{AgCl}}, \mathrm{g} \quad \mathrm{H}_{2} \mathrm{O}_{2}$ Feed Rates}

Lab Scale

28.6

$6 \mathrm{cc} / \mathrm{min}$.

Pilot Plant

12,500

$2.6 \mathrm{~L} / \mathrm{min}$.

\section{Regents Needed and Secondary Waste Generation}

One of the most important goals for the silver recovery process is to minimize the generation of secondary waste $(\mathrm{NaCl})$. Table 4 shows the amounts of secondary waste generated at the optimal condition is $1.62 \mathrm{~kg} \mathrm{NaCl}$ per $\mathrm{kg}$ of chlorinated organic fed to $\mathrm{MEO}$, assuming the excess $\mathrm{NaOH}$ is neutralized with $\mathrm{HCl}$.

Table 4

\begin{tabular}{|c|c|c|c|c|c|c|}
\hline MEO F & & $\underline{\mathrm{AgCl}}$ & $\underline{\mathrm{NaOH}}$ & $\mathrm{H}_{2} \mathrm{O}_{2}$ & $\underline{\mathrm{NaC}}$ & Generate \\
\hline kgmol & $\mathrm{kg}$ & kgmol & kgmol & $\mathrm{L}$ & $\mathrm{kg}$ & $\mathrm{kg} / \mathrm{kg}$ \\
\hline 1 & 62 & 1.37 & 1.71 & 411 & 100 & 1.62 \\
\hline
\end{tabular}

* Halogenated Wastes per Ref. 1

\section{Conclusions}

1. An efficient process has been developed in the lab-scale to convert silver chloride into silver nitrate. The conversion efficiency is better than $90 \%$.

2. The process is non-toxic, low temperature, and does not involve the use of hazardous reagents.

3. The process is economical. The reagents required are sodium hydroxide and hydrogen peroxide which are inexpensive.

4. Generation of secondary waste is small due to the low stoichiometry of $\mathrm{NaOH}$ used for the conversion. 


\section{References}

1. "Mixed Waste Management Facility-Conceptual Design Report", UCRL-Prop11676, L-17293, 1994

2. "Recovery of Silver from and Some Uses for Waste Silver Chloride", J.A.

Murphy, A.H. Ackerman, and J.K. Heeren, J. Chem. Ed., 68(7), p.602, 1991.

3. "Process for Making a Silver Nitrate Solution", L. Rosato, M. Blais, European Patent Application, EP 0568259 A1, 1993. 
Fig. 2 Conversion of $\mathrm{AgCl}$ into $\mathrm{AgNO} 3$ at various $\mathrm{NaOH}$ Stoichiometries

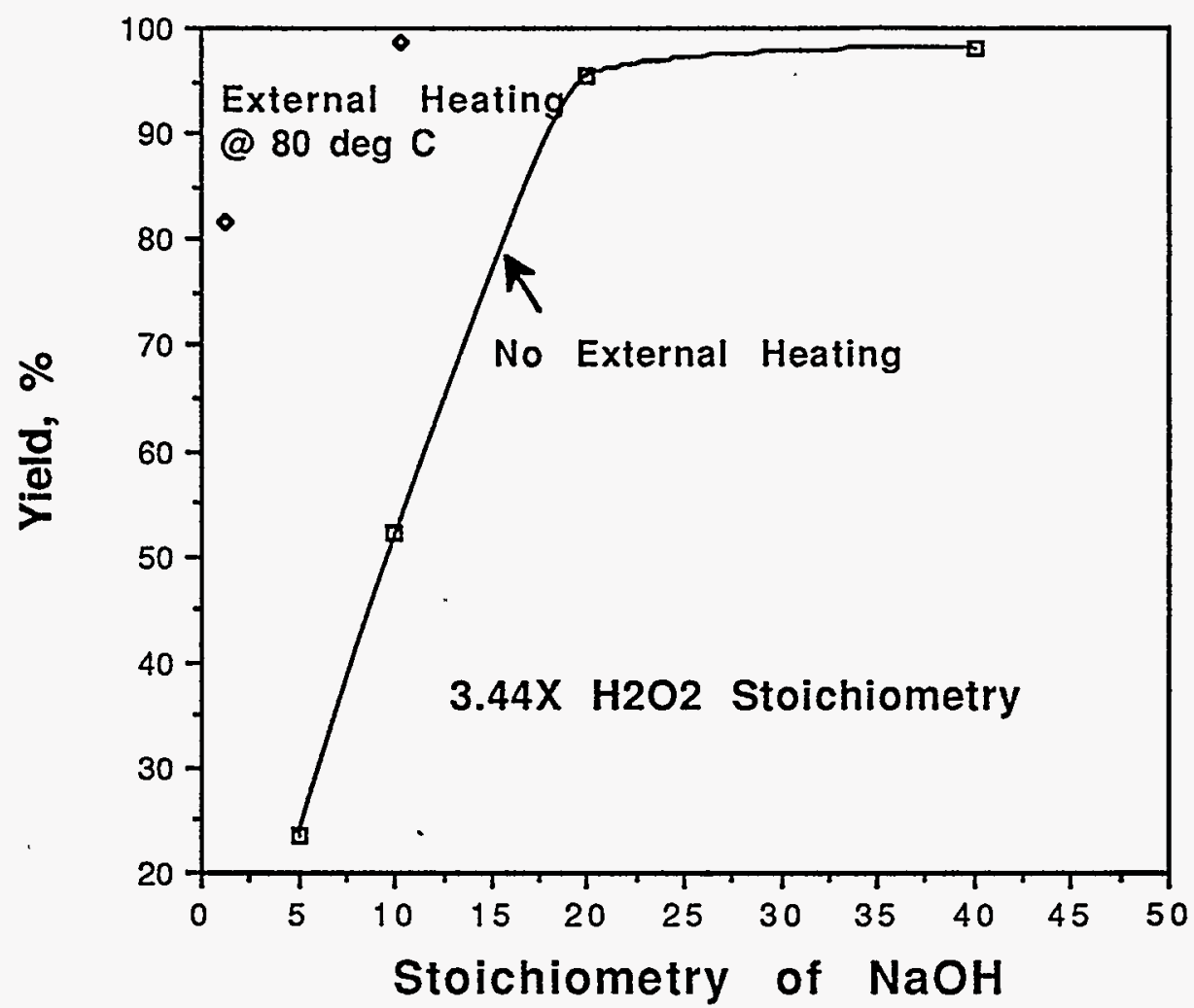


Fig. 3 Effect of $\mathrm{H} 2 \mathrm{O} 2$ Stoichiometry on Conversion Efficiency

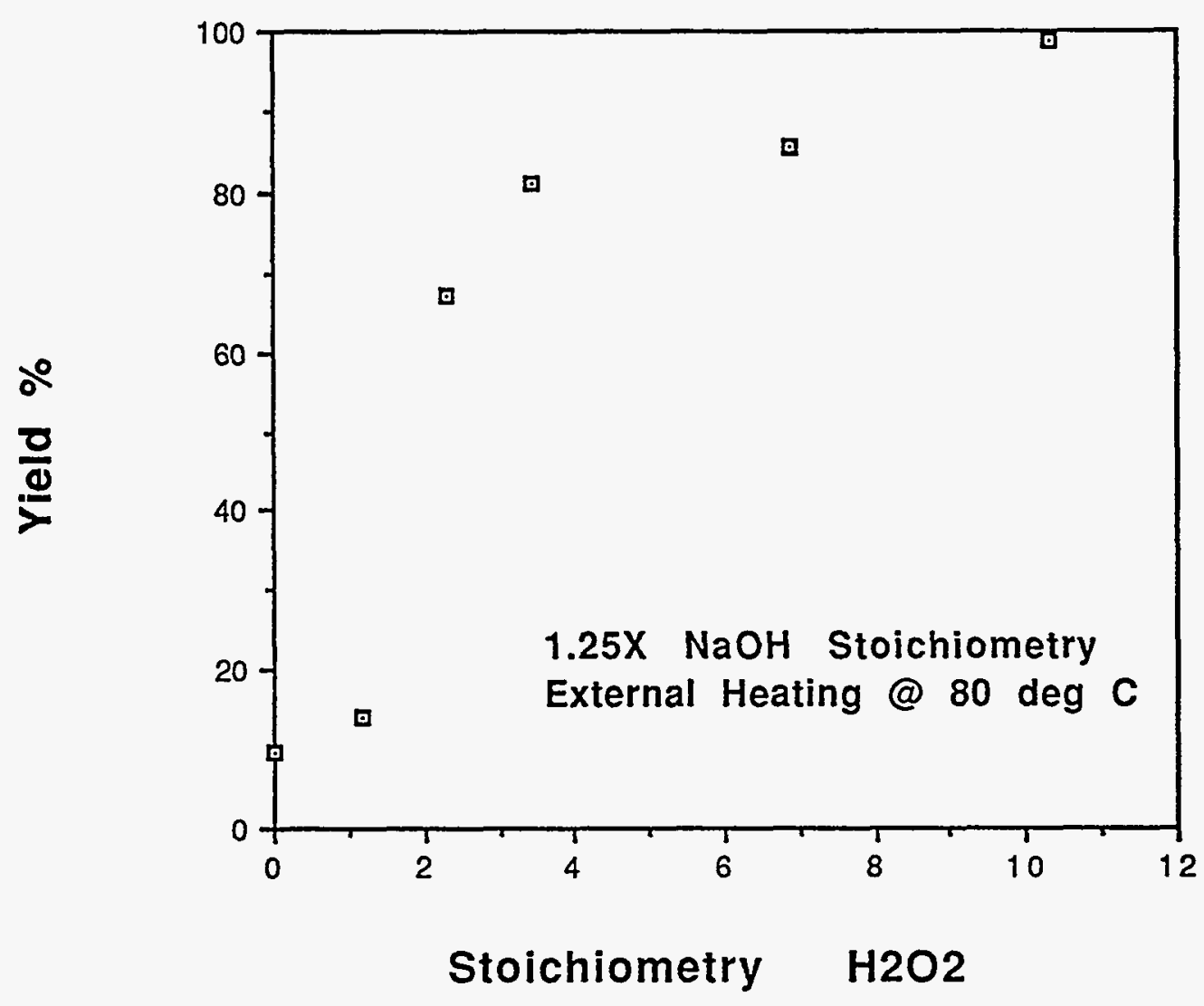


Fig. 4 Conversion Vs. Reaction Time

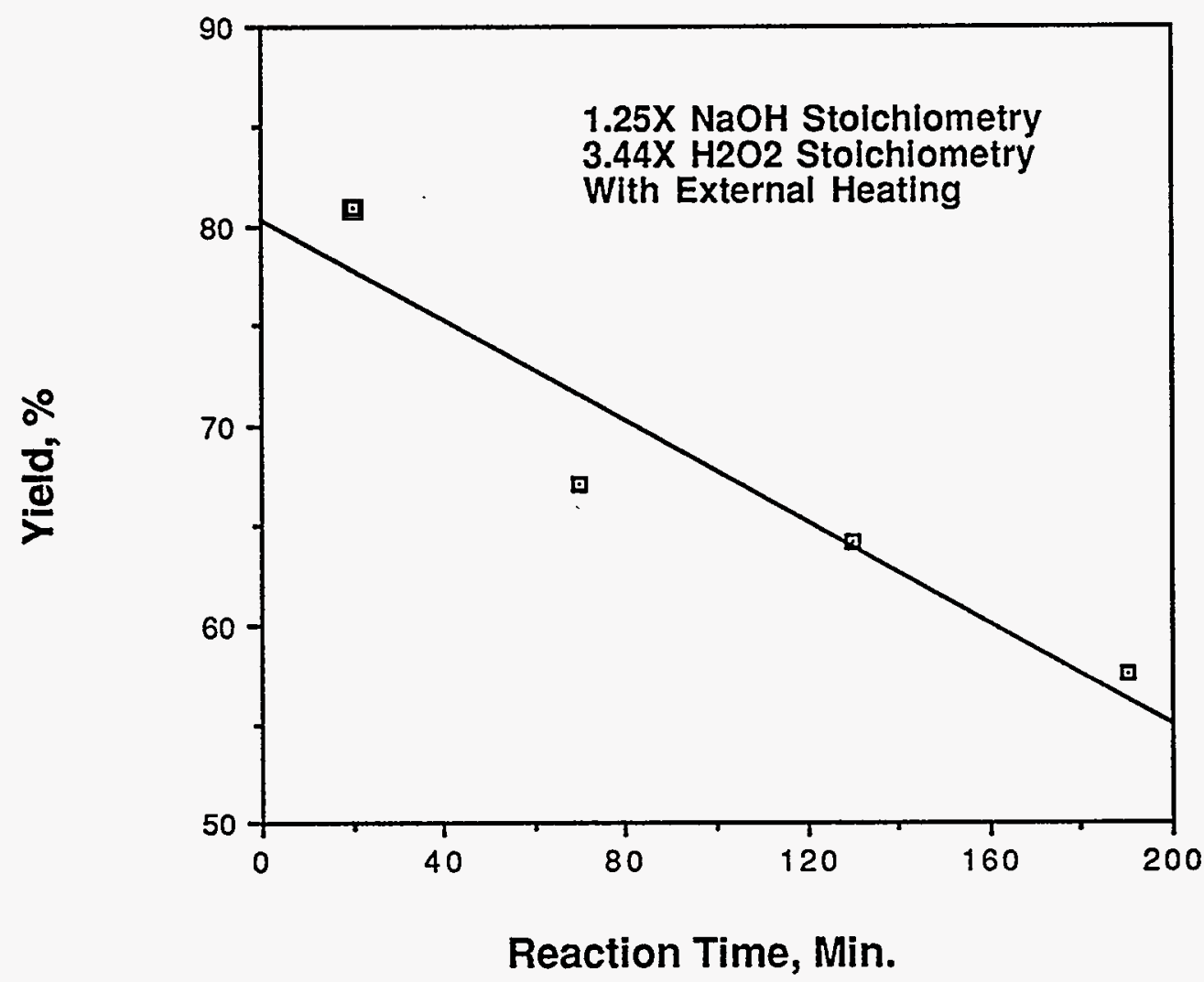


Fig. 5 Solution Reuse Study

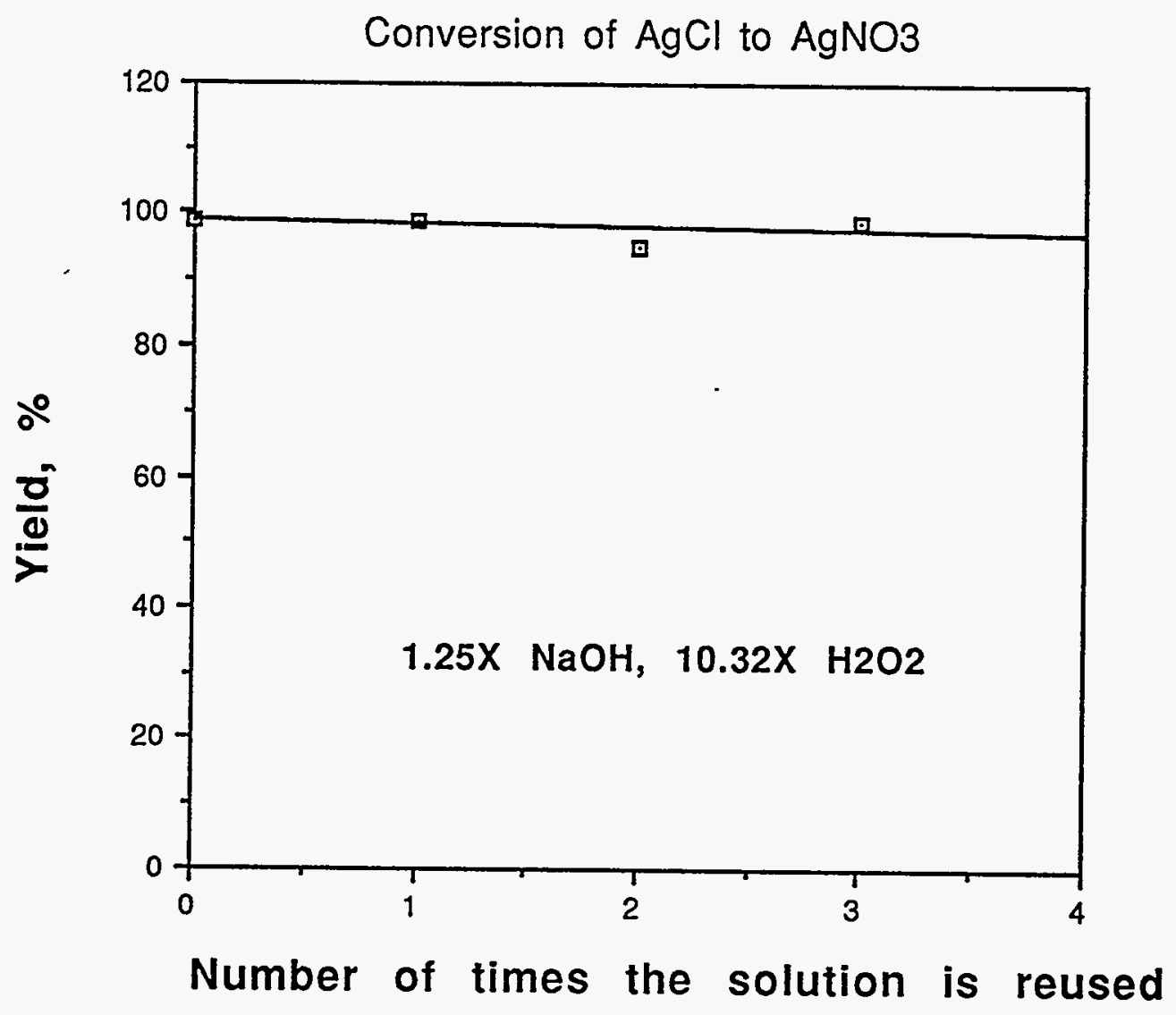


Fig. $6 \mathrm{Ag}$ to salt ratio in the waste water as a function of the number of times the solution is reused

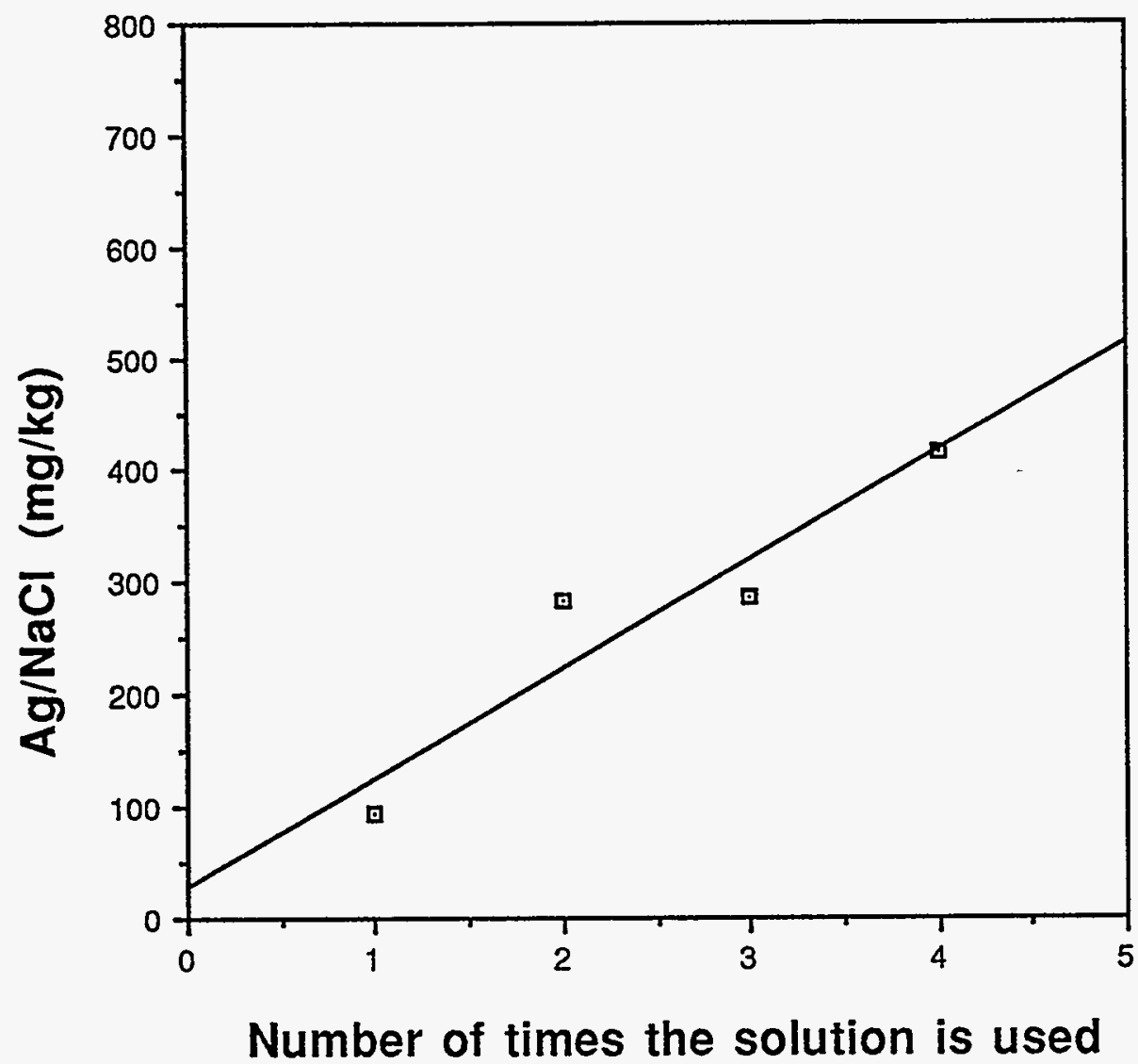



Technical Information Department - Lawrence Livermore National Laboratory University of California - Livermore, California 94551

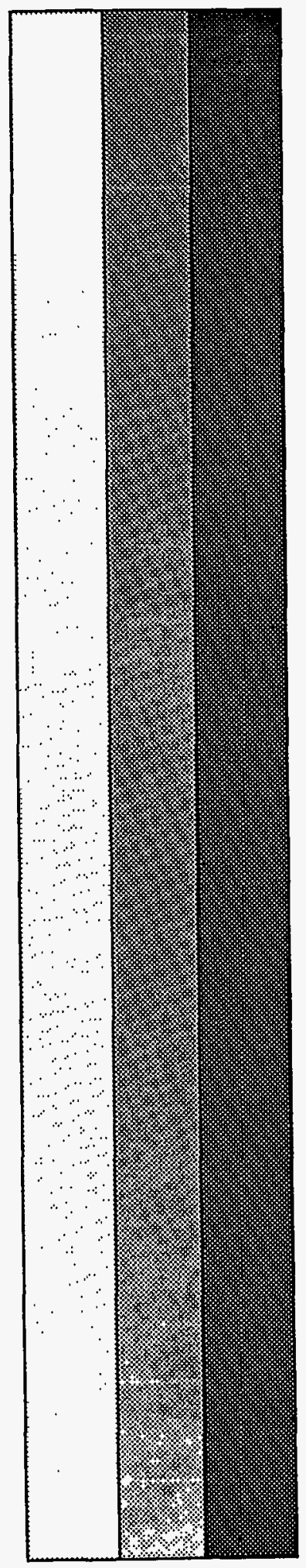

